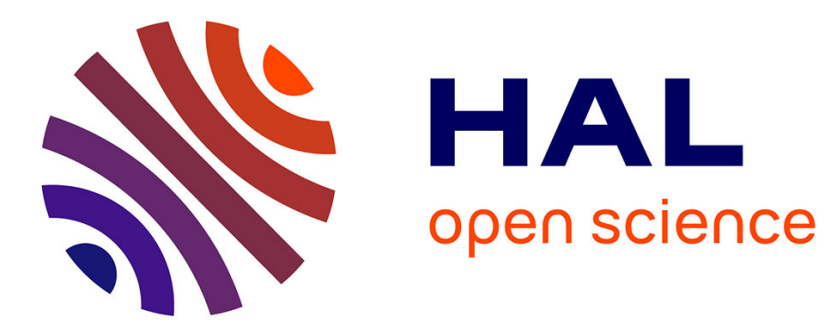

\title{
Simulation of an octahedral random network by computer
}

\author{
Jean-Marc Greneche, J. Teillet, J.M.D. Coey
}

\section{To cite this version:}

Jean-Marc Greneche, J. Teillet, J.M.D. Coey. Simulation of an octahedral random network by computer. Journal de Physique, 1987, 48 (10), pp.1709-1714. 10.1051/jphys:0198700480100170900 . jpa-00210611

\section{HAL Id: jpa-00210611 https://hal.science/jpa-00210611}

Submitted on 1 Jan 1987

HAL is a multi-disciplinary open access archive for the deposit and dissemination of scientific research documents, whether they are published or not. The documents may come from teaching and research institutions in France or abroad, or from public or private research centers.
L'archive ouverte pluridisciplinaire HAL, est destinée au dépôt et à la diffusion de documents scientifiques de niveau recherche, publiés ou non, émanant des établissements d'enseignement et de recherche français ou étrangers, des laboratoires publics ou privés. 
Classification

Physics Abstracts

$61.16-61.40$

\title{
Simulation of an octahedral random network by computer
}

\author{
J. M. Greneche $\left({ }^{1}\right)$, J. Teillet $\left({ }^{2}\right)$ and J. M. D. Coey $\left({ }^{3}\right)$ \\ (1) Laboratoire de Spectrométrie Mössbauer, Université du Maine, 72017 Le Mans Cedex, France \\ ( ${ }^{2}$ L.P.C.M., Institut National des Sciences Appliquées, 76130 Mont-Saint-Aignan, France \\ $\left({ }^{3}\right)$ Department of Pure and Applied Physics, Trinity College, Dublin 2, Ireland
}

(Reçu le 5 février 1987, accepté le 16 juin 1987)

\begin{abstract}
Résumé. - Nous décrivons un algorithme qui permet de simuler un réseau aléatoire d'octaèdres joints par les sommets sans liaison pendante et représentant la structure d'un amorphe type $\mathrm{AB}_{3}$. La densité, les fonctions de distributions radiales, les distributions angulaires et les statistiques d'anneaux sont reportées. Les gradients de champ électrique (incluant uniquement la contribution monopolaire) sont calculés sur les sites de fer en utilisant une méthode de charges ponctuelles : la distribution de séparation quadripolaire déduite est en bon accord avec les résultats de spectrométrie Mössbauer concernant la variété amorphe $\mathrm{FeF}_{3}$.
\end{abstract}

\begin{abstract}
An algorithm is described which simulates a random network of corner-sharing octahedra with no dangling bonds, representing the structure of amorphous $A_{3}$ compounds. The density, the partial radial distribution functions, bond angle distributions and ring statistics are presented. The monopolar electric field gradients at the iron sites of this model are also calculated, using a point charge model : the distribution deduced is in a good agreement with Mossbauer data on a-FeF .
\end{abstract}

\section{Introduction.}

Some laboratory models have recently been built to represent the structures of amorphous $\mathrm{AB}_{3}$ ionic compounds such as $\mathrm{FeF}_{3}$ and $\mathrm{WO}_{3}$ prepared by vapour quenching techniques. These models were continuous random networks composed of cornersharing octahedra, built from 516 ball and spoke units [1] or 300 plastic octahedra [2]. Density, partial radial distribution functions, bond angle distributions and ring statistics were calculated from these models, but could not be directly compared with experimental results because there are little published data. Computer relaxation of these two networks was carried assuming harmonic potentials. The monopolar electric field gradient (E.F.G.) distribution was evaluated for these models, using a point charge model adapted for amorphous structures [3], but the results were questionable because of the small size of such networks.

An alternative approach, direct computer simulation of a dense random packing model involving two kinds of hard spheres, was used by Lines [4] and the E.F.G. at iron sites was computed using a point charge model. The E.F.G. distribution agrees with
Mossbauer data and exhibits an equal probability for positive and negative values of the principal component [5]. However, Lines'model does not respect sixfold coordination of $A$ atoms, which is a likely constraint on any amorphous ionic $\mathrm{AB}_{3}$ structure.

Our two previous models $[1,2]$, are used here as starting point for generating much larger models by computer, respecting the coordination. We present here an algorithm for simulating such structures and give some characteristics of a model with $1251 \mathrm{~A}$ atoms. This model is a relaxed octahedral random network which should provide a starting point for comparison with the structures of real amorphous materials. The general approach to modelling amorphous structures has been described by Finney [6].

\section{Algorithm to generate random network of $A$ atoms.}

The model starts from a « nucleus » made of nodes which represent $A$ atoms, whose bonds (except for surface atoms) respect six-fold coordination so that the nodes are centres of corner-sharing octahedra. 
The algorithm consists in growing such a « nucleus» by adding A atoms and connecting bonds between them. It was developed after considering the following physical criteria :

- the 6-fold A-A coordination,

- the steric encumbrance of the atoms,

- the presence of odd-membered and evenmembered rings.

The addition of nodes (A atoms) to the nucleus must take account of steric considerations : in the case of corner-sharing octahedra, the ideal A/B radius ratio for close packing places a lower limit on the A-A distance; however, slightly shorter or larger A-A distances are possible and are related to distortions of the shape of the octahedra and bending the A-B-A bonds. It can be evidenced by diffraction techniques (neutron, X-rays or E.X.A.F.S.), whose results indicate a distribution of A-A distances.

In any particular « nucleus », two kinds of atoms can be distinguished : the surface atoms which do not respect the 6-fold coordination and the core atoms which are connected to 6 well-defined neighbours. The program selects the surface atom nearest to the centroid of the nucleus, called $A_{1}$; again, among the surface atoms, that closest to $A_{1}$ is selected : $A_{2}$. To introduce steric considerations, the distance between atoms $A_{1}$ and $A_{2}$ is compared to the ideal distance $d_{\mathrm{A}-\mathrm{A}}$; also the neighbourood of $A_{1}$ and $A_{2}$ have to be taken into account: the different possibilities of adding and bonding atoms are discussed in detail below for the case of amorphous $\mathrm{FeF}_{3}$.

\section{Introduction of $B$ atoms and relaxation.}

Growth of the nucleus, respecting the coordination and steric constraints leads to an A-network whose topology is well-defined. The B atoms are then located at the middle of the A-A bonds. At this stage of the procedure, the A-A, A-B, B-B bonds and the $A$ and $B$ atomic positions are in the computer memory.
A relaxation process of $A$ and $B$ positions is then carried out iteratively, assuming harmonic A-B and B-B potentials of form

$$
V_{i}=\sum_{j} C_{i j}\left(d_{i j}-d_{i j}^{0}\right)^{2}
$$

where $C_{i j}$ is a constant which is non-zero only for nearest neighbour $A-B$ interactions and first and second neighbour B-B interactions (in the same octahedral unit). The topology of the model is unchanged after such a relaxation process.

In this way, a relaxed continuous random network of corner-sharing octahedra with no dangling bonds can be generated by computer, of any desired size. From the atomic positions, it is possible to calculate realistically a number of physical properties.

\section{Numerical data in the case of $\mathrm{FeF}_{3}$.}

The starting nucleus is made of 200 nodes representing the $\mathrm{Fe}$ atomic positions and the bonds taken from the core of the ball and spoke model constructed by hand a few years ago [1].

A comparison of the magnetic properties of various phases of $\mathrm{FeF}_{3}$ can be used as a guide for the ring statistics which can be expected in the model: indeed the frequency of odd-membered rings and the magnetic ordering temperatures of the crystalline varieties of $\mathrm{FeF}_{3}$ are strongly correlated as shown in table I ; this appears to be a consequence of frustration of antiferromagnetic interactions in odd-membered rings. Since amorphous $\mathrm{FeF}_{3}$ is found to order speromagnetically at only $39 \mathrm{~K}$ [7], it is reasonable to choose an algorithm which have to favour the creation of 3 and 5 membered rings in the amorphous structure. However, we found that a minimum amount of even-membered rings $(\approx 40 \%$ as shown in Fig. 1) was needed to avoid the growth of the model stopping prematurely. The proportion of four-membered rings was optimized in order to allow a «gentle " growth of the model.

According to the steric encumbrance through the

Table I. - Ratios of ring statistics, densities and Curie temperatures for the three crystalline forms of $\mathrm{FeF}_{3}$.

\begin{tabular}{|c|c|c|c|c|c|c|c|c|c|}
\hline & $\begin{array}{c}n-n \\
n=3 \\
\%\end{array}$ & $\begin{array}{c}\text { mbered } \\
n=4 \\
\%\end{array}$ & $\begin{array}{c}n \text { per } \\
n=5 \\
\%\end{array}$ & $\begin{array}{c}\mathrm{m} \\
\substack{\% \\
\%}\end{array}$ & $\langle n\rangle$ & $\begin{array}{l}\text { Total } \\
\text { rings per } \\
\text { atom }\end{array}$ & $\underset{\mathrm{g} / \mathrm{cm}^{3}}{\rho}$ & $\begin{array}{l}T \\
\mathrm{~K}\end{array}$ & Ref. \\
\hline $\begin{array}{l}\text { Rhombohedral } \\
\mathrm{FeF}_{3}\end{array}$ & 0 & 100 & 0 & 0 & 4.00 & 3 & 3.61 & 363 & [11] \\
\hline $\begin{array}{l}\text { Hexagonal } \\
\mathrm{FeF}_{3}\end{array}$ & 16.7 & 66.7 & 0 & 16.7 & 4.17 & 3 & 3.33 & 110 & [12] \\
\hline $\begin{array}{c}\text { Pyrochlore } \\
\mathrm{FeF}_{3}\end{array}$ & 50 & 0 & 0 & 50 & 4.50 & 3 & 2.74 & 22 & [13] \\
\hline
\end{tabular}




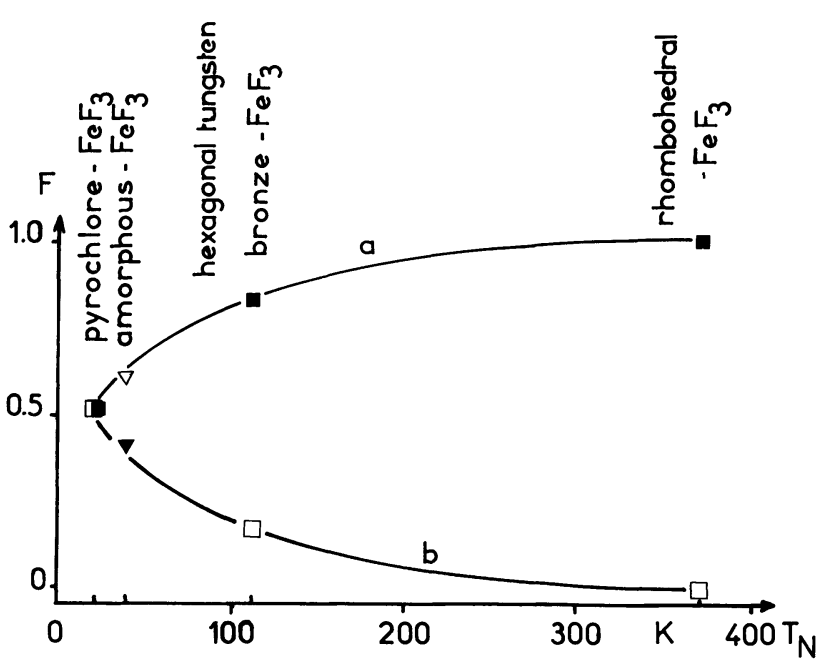

Fig. 1. - Proportion of even-membered rings (full symbols) and odd-membered rings (white symbols) reported as a function of the ordering temperature for the three crystalline forms (squares) and the amorphous variety (triangles) of $\mathrm{FeF}_{3}$.

value of $q=d_{\mathrm{A} 1-\mathrm{A} 2} / d_{\mathrm{Fe}-\mathrm{Fc}}\left(\mathrm{A}_{1}\right.$ and $\mathrm{A}_{2}$ were defined in the above section) and topological criteria through the presence of odd and even-membered rings, different cases are considered when adding $\mathrm{A}$ atoms to the «nucleus»:

1. $0.97 \leq q \leq 1.03$ : a bond is created between the $\mathrm{A}_{1}$ and $\mathrm{A}_{2}$ atoms.

2. $0.50 \leq q<0.97$ and $1.03<q \leq 1.30$ : local rearrangement is permitted to increase or to decrease the distance between $A_{1}$ and $A_{2}$ by successive small shifts along $A_{1}-A_{2}$ direction until condition 1 is satisfied.

3. $1.30<q<1.50$ : one extra atom $\mathrm{A}_{3}$ is generated, connected to $A_{1}$ and $A_{2}$. The positions are such that $A_{1}, A_{2}, A_{3}$ and the centroid of the nucleus lie in the same plane with

$$
d_{\mathrm{A} 1-\mathrm{A} 3}=d_{\mathrm{A} 2-\mathrm{A} 3}=d_{\mathrm{Fe}-\mathrm{Fe}} .
$$

4. $1.80<q<2.40$ : two extra atoms $\mathrm{A}_{3}$ and $\mathrm{A}_{4}$ are. generated, bonded respectively to $A_{1}$ and $A_{2}$ and to each other. Their positions are calculated by a similar method to that of case 3 . So we have

$$
d_{\mathrm{A} 1-\mathrm{A} 3}=d_{\mathrm{A} 3-\mathrm{A} 4}=d_{\mathrm{A} 4-\mathrm{A} 2}=d_{\mathrm{Fe}-\mathrm{Fc}} .
$$

5. $1.50 \leq q \leq 1.80$ : if $\mathrm{A}_{1}$ and $\mathrm{A}_{2}$ are connected, 2 atoms will be generated; if not, only one atom is generated. Their positions are determined by an analogous method.

6. $q>2.40$ or $q<0.50:$ the program stops itself and the relaxation process is carried out over the whole of the existing "nucleus » after introducing the $\mathrm{B}$ atoms.
After the existing nucleus with both $A$ and $B$ atoms has been relaxed, growth is continued to produce a new nucleus and so on. Growth stops when the model reaches a size limit set at the beginning.

In order to keep the octahedra as regular as possible, the distances $d_{\mathrm{BB} 1}^{0}$ and $d_{\mathrm{BB} 2}^{0}$ are respectively equal to $\sqrt{2} d_{\mathrm{AB}}^{0}$ and $2 d_{\mathrm{AB}}^{0}$, as shown in figure 2 . The

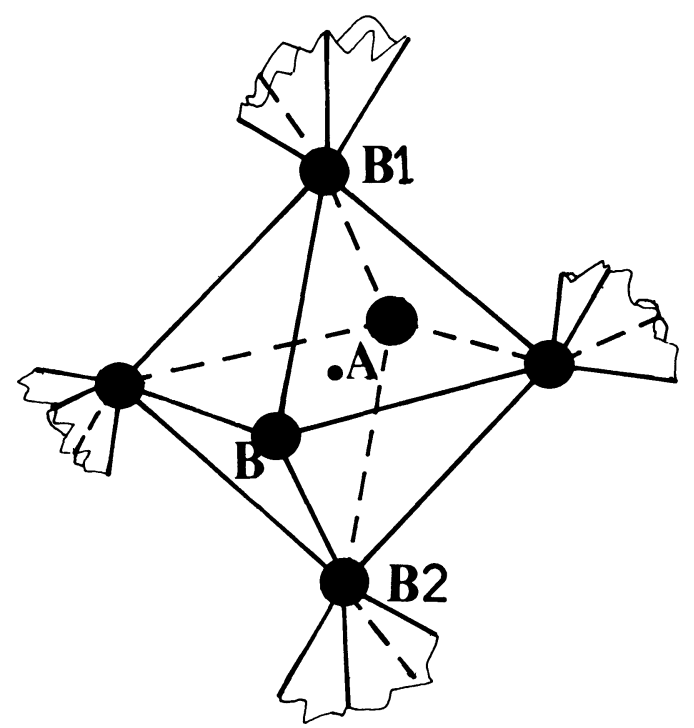

Fig. 2. - Neighbourood of iron and fluorine atoms in an octahedron.

ideal A-B distance, $d_{\mathrm{Fe}-\mathrm{F}}$ in this case, is taken equal to $1.95 \AA$, a value obtained from E.X.A.F.S. experiments on amorphous $\mathrm{FeF}_{3}$ prepared by vapour quenching technique [8]. The relative values of $C_{i j}$ were chosen to minimize the energy so

$$
C_{\mathrm{BB} 1}=C_{\mathrm{BB} 2}=C_{\mathrm{BB}} \text { and } C_{\mathrm{AB}} / C_{\mathrm{BB}}=3 \text {, }
$$

which seems in a good agreement with the experimental values of the elastic constants in the case of $\mathrm{RbAlF}_{4}$ [9].

A model containing $1251 \mathrm{Fe}$ atoms was successfully generated, and $3145 \mathrm{~F}$ atoms were included. The shape of the 4396 -atom network was close to a sphere due to the radial growth pattern.

\section{Results and discussion.}

The ring statistics of our model were evaluated, taking into account only internal atoms; only the smallest rings involving two bonds leaving a given A atom in approximately perpendicular directions were counted. The results are presented in table II and compared to the previous hand-built models. The total number of rings per atom for 3, 4, 5, 6 and 7 membered rings is very close to the expected value, 3 , consistent with the chemical formula of the 
Table II. - Ring statistics for the amorphous models.

\begin{tabular}{|c|c|c|c|c|c|c|c|}
\hline $\begin{array}{l}n \text {-membered } \\
\text { ring }\end{array}$ & $\begin{array}{c}n=3 \\
\%\end{array}$ & $\begin{array}{c}n=4 \\
\%\end{array}$ & $\begin{array}{c}n=5 \\
\%\end{array}$ & $\begin{array}{c}n=6 \\
\%\end{array}$ & $\begin{array}{c}n=7 \\
\%\end{array}$ & $\langle n\rangle$ & $\begin{array}{l}\text { Total rings } \\
\text { per atom }\end{array}$ \\
\hline This model & 28.0 & 36.3 & 31.2 & 3.6 & 0.9 & 4.14 & 3.36 \\
\hline $\begin{array}{c}\text { Coey's model } \\
{[1]}\end{array}$ & 8.1 & 46.5 & 42.2 & 2.5 & 0.7 & 4.41 & 4.17 \\
\hline $\begin{array}{c}\text { Octahedral } \\
\text { model } \\
{[2]}\end{array}$ & 15.9 & 38.7 & 37.9 & 7.5 & - & 4.38 & 3.72 \\
\hline
\end{tabular}

amorphous compound. Such ring statistics are in agreement with the growth hypothesis, and are consistent with the reduction of the spin freezing temperature of amorphous $\mathrm{FeF}_{3}$ and the Neel temperature of the hexagonal and pyrochlore forms compared to that of the rhombohedral phase, as shown in figure 1 . Note that the pyrochlore form whose structure is based on tetrahedral groups of octahedral units has only three and six-membered rings but the same number of rings per atom as the rhombohedral form. It orders at $T_{\mathrm{N}}=22 \mathrm{~K}$ as a four-sublattice antiferromagnet with the sublattices oriented at the tetrahedral angle $109^{\circ}$ with respect to each other [13].

The density was calculated on successive spheres, the largest of which contains $460 \mathrm{Fe}$ atoms and $1351 \mathrm{~F}$ atoms. The value obtained, $3.48 \mathrm{~g} / \mathrm{cm}^{3}$, is compared to those of the three crystalline forms of $\mathrm{FeF}_{3}$ in table I. The ideal cubic form $\mathrm{ReO}_{3}$ type structure would have $\rho=3.31 \mathrm{~g} / \mathrm{cm}^{3}$. The density of the present model is therefore $5 \%$ greater than for the ideal $\mathrm{FeF}_{3}$ structure. The algorithm avoids formation of cavities in the amorphous structure larger than those in the pyrochlore form because it rules out dangling bonds and steric considerations prevent the F-Fe-F bonds from approximately $180^{\circ}$.

Radial distribution functions calculated from the relaxed model are presented in figure 3 . They show a fair amount of structure. The Fe-F peakwidth is very similar to that deduced from E.X.A.F.S. experiments [8]. Although, no total radial distribution function have been yet obtained on amorphous $\mathrm{FeF}_{3}$, one is available for amorphous $\mathrm{WO}_{3}[10]$. There is good agreement between those data and the radial distribution function around the cation calculated from our model, as shown in figure 4 [10].

The distribution of bond angles determined on $3145 \mathrm{Fe}-\mathrm{F}-\mathrm{Fe}$ bonds, is presented in figure 5. The average value is $154^{\circ}$ and the fullwidth at half maximum is $40^{\circ}$. In table IV, the Fe-F-Fe angles are reported for the three crystalline forms of $\mathrm{FeF}_{3}$. The shape of the distribution of Fe-F-Fe angles shows

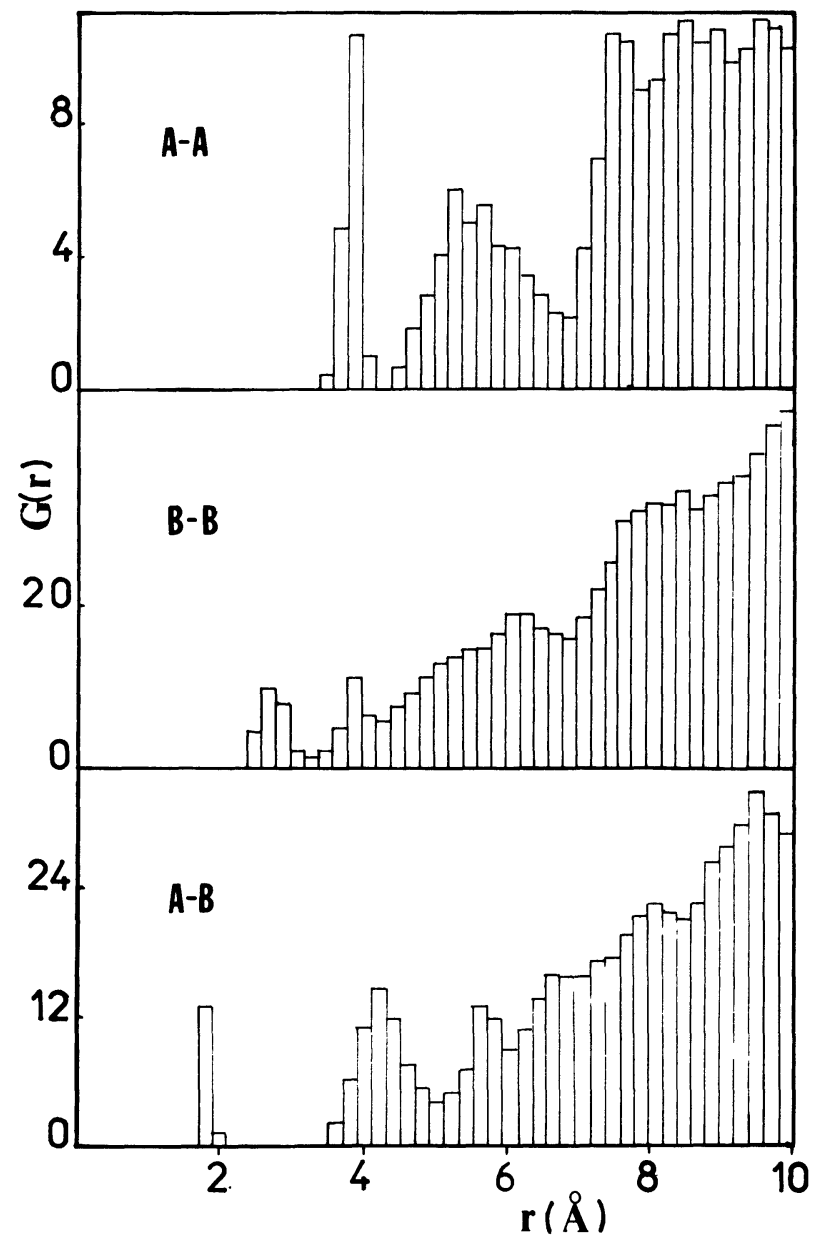

Fig. 3. - Partial radial distribution functions for the simulated random network.

that the criterion of steric encumbrance has been well respected; only $5 \%$ of the Fe-F-Fe angles are observed to be below the lower limit of $135^{\circ}$ established from the $\mathrm{Fe} / \mathrm{F}$ radius ratio of 0.414 . Furthermore, the different parameters characterizing the shape of the octahedral unit are reported in table III and compared to those of the previous 


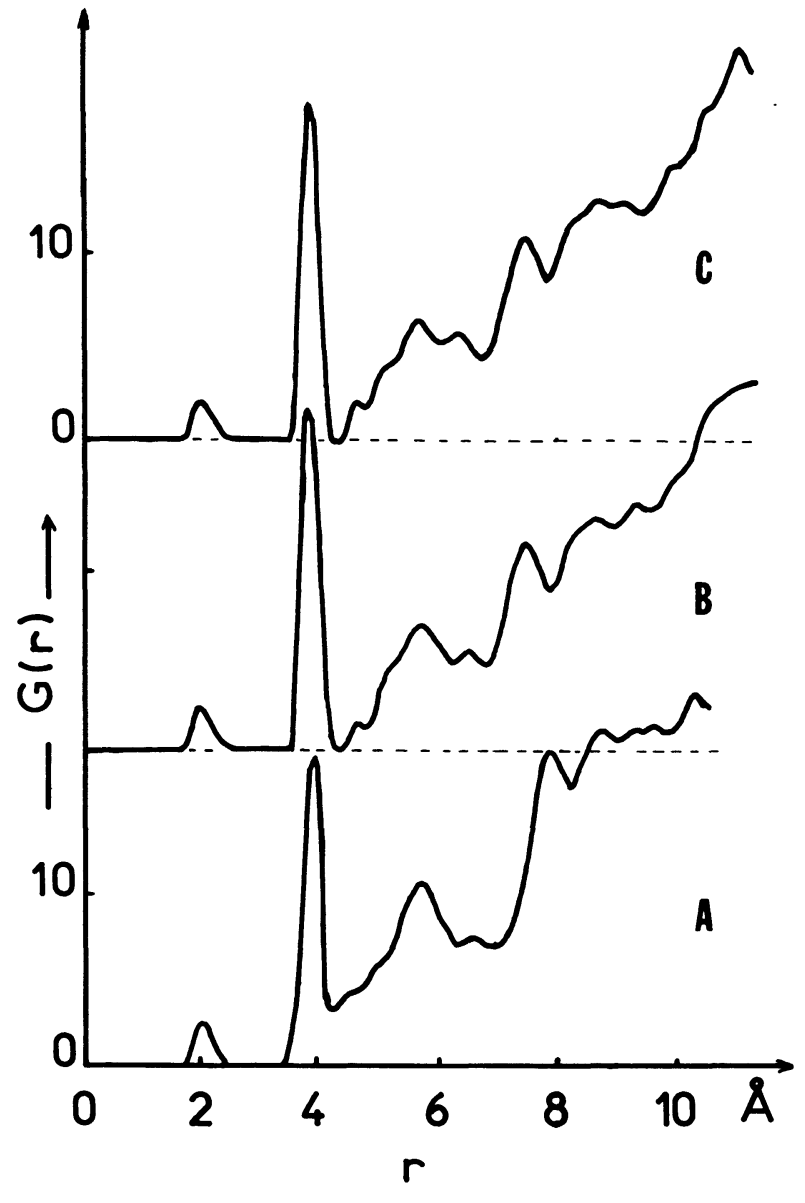

Fig. 4. - Radial distribution function around the tungsten atom calculated from the simulated random network (A), obtained for evaporated $\mathrm{WO}_{3}(\mathrm{~B})$ and sputtered $\mathrm{WO}_{3}$ (C) (adapted from Fig. 4 of [10]).

hand-built models, once relaxed with the above harmonic potentials : the octahedral unit is weakly distorted.

The calculation of the monopolar E.F.G. has been carried out using the point charge model, adapted for amorphous structures by considering successive spheres [3]. Figure 6 shows the distribution of quadrupolar splitting calculated on 495 iron sites. The

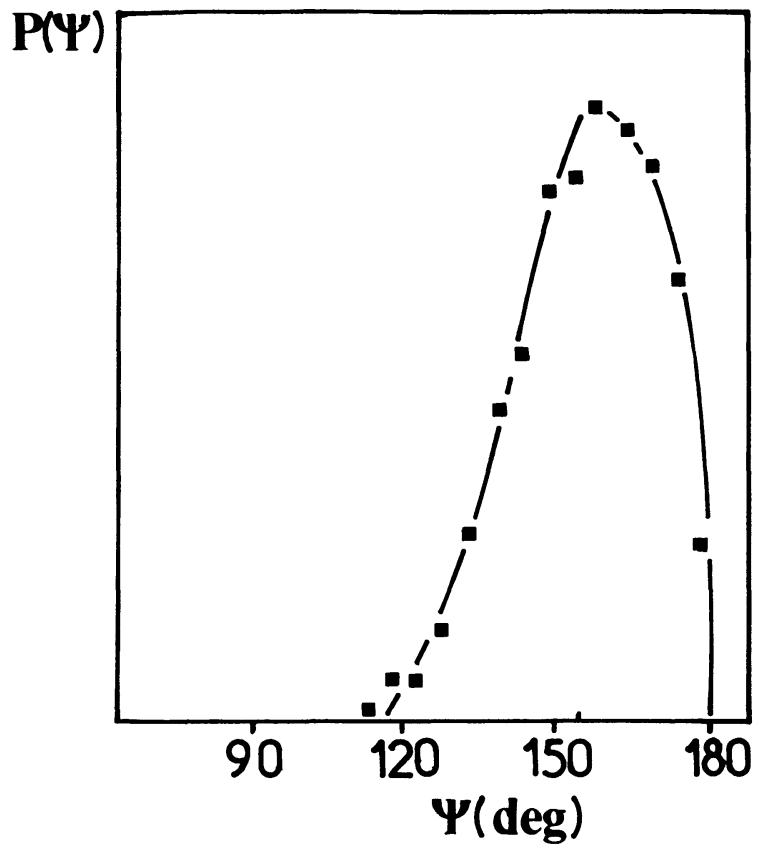

Fig. 5. - ABA bond angle distribution for the simulated random network.

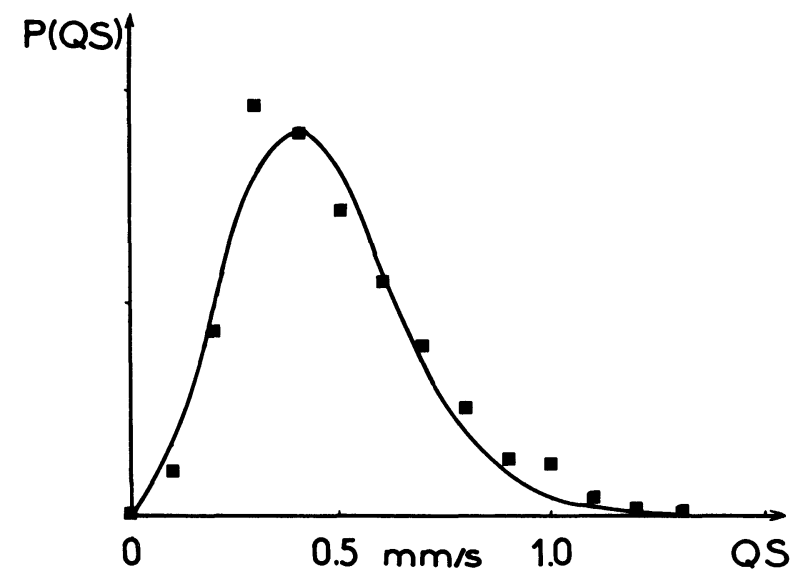

Fig. 6. - Quadrupole splitting distribution calculated from the present model (squares) and the solid curve represents the analytic development proposed by Czjzek with $d=2.9$ [15].

Table III. - Characteristics of relaxed amorphous models.

\begin{tabular}{c|c|c|c|c|c|c|c|c|c} 
& Density & $\begin{array}{c}d_{\mathrm{Fc}-\mathrm{F}} \\
(\mathrm{A})\end{array}$ & $\begin{array}{c}d_{\mathrm{F}-\mathrm{F}} \\
(\mathrm{A})\end{array}$ & $\begin{array}{c}d_{\mathrm{Fc}-\mathrm{Fc}} \\
(\mathrm{A})\end{array}$ & $\begin{array}{c}\mathrm{Fe}-\mathrm{F}-\mathrm{Fe} \\
(\mathrm{degrees})\end{array}$ & $\begin{array}{c}\mathrm{F}-\mathrm{F}-\mathrm{F} \\
(\mathrm{deg} r e e s)\end{array}$ & $\begin{array}{c}\mathrm{F}-\mathrm{Fe}-\mathrm{F} \\
(\mathrm{degrees})\end{array}$ & $\alpha$ & $\beta$ \\
\hline This model & $3.48(5)$ & $1.95(5)$ & $2.75(29)$ & $3.77(16)$ & $154(14)$ & $60(11)$ & $90(13)$ & $-0.00(1)$ & $-0.00(2)$ \\
\hline Coey's model & $3.35(8)$ & $1.92(3)$ & $2.72(19)$ & $3.79(17)$ & $162(11)$ & $60(7)$ & $90(9)$ & $0.00(1)$ & $0.00(1)$ \\
\hline $\begin{array}{c}\text { Octahedral } \\
\text { model [2] }\end{array}$ & $3.68(18)$ & $1.92(5)$ & $2.72(17)$ & $3.61(24)$ & $143(17)$ & $60(5)$ & $90(7)$ & $-0.00(1)$ & $-0.00(1)$
\end{tabular}


Table IV. - Structural characteristics of the three forms of crystalline $\mathrm{FeF}_{3}$.

\begin{tabular}{l|c|c|c|c} 
& $\begin{array}{c}d_{\mathrm{Fc}-\mathrm{F}} \\
(\mathrm{A})\end{array}$ & $\begin{array}{c}d_{\mathrm{F}-\mathrm{F}} \\
(\mathrm{A})\end{array}$ & $\begin{array}{c}d_{\mathrm{Fc}-\mathrm{Fc}} \\
(\mathrm{A})\end{array}$ & $\begin{array}{c}\mathrm{Fe}-\mathrm{F}-\mathrm{Fe} \\
(\text { degrees})\end{array}$ \\
\hline Rhombohedral $\left(^{1}\right)$ & 1.92 & 2.72 & 3.73 & 152.15 \\
\hline Hexagonal $\left(^{(2)}\right.$ & $1.91-1.92$ & 2.75 & $3.70-3.78$ & $142.3-150.7$ \\
\hline Pyrochlore $\left(^{3}\right)$ & 1.93 & 2.757 & 3.64 & 141.65
\end{tabular}

$\left({ }^{1}\right)$ Values at $300 \mathrm{~K}$.

(2) Values at $4.2 \mathrm{~K}[13]$.

$\left({ }^{3}\right)$ Values at $2.5 \mathrm{~K}[13]$

shape of this distribution is well reproduced by that calculated from the analytic development proposed by Czjzek [15] $P(\Delta)=\left(\Delta^{d-1} / \sigma^{d}\right) \exp \left(-\Delta^{2} / 2 \sigma^{2}\right)$ with $d=2.9$ as shown in figure 6 . In addition, the calculated quadrupolar splitting distribution shows a qualitative agreement with experimental data deduced from Mössbauer spectroscopy recorded at room temperature on amorphous $\mathrm{FeF}_{3}[14,16]$, for which a detailed discussion will be given elsewhere [3].

\section{Conclusion.}

A random octahedral structure with no dangling bonds has been successfully generated by computer.
The ring statistics are consistent with the low spin freezing temperature of the amorphous form of $\mathrm{FeF}_{3}$ compared with some of the crystalline phases. The radial distribution functions are well resolved, the $\mathrm{FeF}_{6}$ octahedra are weakly distorted and the steric encumbrance is well respected. The calculations of the E.F.G. well reproduce the Mossbauer results on $\mathrm{a}-\mathrm{FeF}_{3}$.

\section{Acknowledgments.}

The authors wish to thank Dr. J. Cadogan, Prof. F. Varret and Prof. D. L. Weaire for fruitful discussions. This work has received financial support through the N.B.S.T./C.N.R.S. exchange scheme.

\section{References}

[1] Coey, J. M. D. and Murphy, P. J. K., J. Non-Cryst. Solids 50 (1982) 125.

[2] Greneche, J. M., Teillet, J. and Coey, J. M. D., J. Non-Cryst. Solids 83 (1986) 27.

[3] Greneche, J. M., Varret, F. and Teillet, J., $J$. Physique (submitted).

[4] Lines, M. E., Phys. Rev. B 21 (1980) 5793.

[5] Lines, M. E., J. Non-Cryst. Solids 46 (1981) 1.

[6] FinNEY, J. L., Nature 266 (1977) 309.

FinNey, J. L., Amorphous Metallic Alloys, editor Luborsky, Butterworths Monographs in Materials, 1983, p. 42.

[7] Ferey, G., Varret, F. and Coey, J. M. D., J. Phys. C 12 (1979) L531.

[8] Greneche, J. M., Le Bail, A., Leblanc, M., Mosset, A., VArret, F., Galy, J. and Ferey, G., J. Phys. C (accepted).

[9] Bulou, A., Thesis Le Mans (1985).

[10] Zeller, H. R. and Beyeler H. U., Appl. Phys. 13 (1977) 231.

[11] Wertheim, G. K., Guggenheim, H. J. and Buchanan, D. N. E., Phys. Rev. 169 (1968) 165.
[12] Calage, Y., Leblanc, M., Ferey, G. and Varret, F., J. Mag. Mag. Mat. 44 (1984) 195.

Lopez-Herrera, M. E., Varret, F., Calage, Y. and Ferey, G., J. Mag. Mag. Mat. 44 (1984) 304.

[13] Calage, Y., Zemirli, M., Greneche, J. M., VARret, F., DE PAPE, R. and FEREy, G., J. Solid State Chem. (1987) at press.

Ferey, G., De Pape, R., Leblanc, M. and PanNetier, J., Rev. Chim. Minér. 23 (1986) 474.

[14] Lopez-Herrera, M. E., Thesis, Le Mans (1983).

Ferey, G., Leclerc, A. M., de Pape, R., Mariot, J. P. and VARret, F., Solid State Commun. 29 (1979) 477.

[15] Czjzek, G., Fink, J., Gotz, F., Schmidt, H., Coey, J. M. D., Rebouillat, J. P. and Lienard, A., Phys. Rev. B 23 (1981) 2513.

Czjzek, G., Phys. Rev. B 25 (1982) 4908.

[16] Greneche, J. M., Varret, F., Leblanc, M. and FEREY, G., Solid State Commun. 63 (1987) 435. 